\title{
Biosorpsi Krom Total dalam Limbah Cair Batik dengan Biosorben yang Dikemas dalam Kantung Teh Celup
}

\author{
Sri Lestari ${ }^{2,3}$ Sudarmadji ${ }^{1}$, S. Djalal Tandjung ${ }^{1}$, Sri Juari Santosa ${ }^{2}$ \\ ${ }_{1}^{1}$ Prodi IImu Lingkungan, Sekolah Pascasarjana, Universitas Gadjah Mada \\ Jalan Teknika Utara, Pogung Yogyakarta 55281 email: sudarmadji@ugm.ac.id. \\ ${ }^{2}$ Prodi Kimia Fakultas MIPA, Universitas Gadjah Mada \\ Jalan Pancasila, Yogyakarta 55281 email: sjuari@ugm.ac.id. \\ ${ }^{3}$ Fakultas Biologi, Universitas Jenderal Soedirman \\ Jalan dr. Suparno 62 Purwokerto 53122 email: srilestari.bio@unsoed.ac.id.
}

\begin{abstract}
Chromium content on batik wastewater has been reduced by biosorption using cheap, abundant, and easily obtained biosorbent, such as Sargassum cinereum and Pleurotus ostreotus baglog waste. Biosorbent surface can be expanded by reducing its particle size. However, small size particle very difficult to be applied, but it application can be improved through shape simplification or tea bag packaging. This research aims to obtain the optimum of biosorbent ratio and particle size in chromium adsorption. This experimental research was conducted using Spilt Plot Design. The obtained data were analyzed using F-test with the significance level of $5 \%$. The result showed that the optimum adsorption percentage was obtained in biosorbent ratio of 3:1 with particle size of $425-675 \mu \mathrm{m}$ that is $62.69 \%$. Biosorbent packed in the tea bags is effective to removal chromium in batik wastewater.
\end{abstract}

Key Words : batik waste water, biosorption, chromium, tea bag packing, chromium

\begin{abstract}
Abstrak
Krom dalam limbah cair batik dapat dikurangi dengan metode biosorpsi menggunakan biosorben yang murah, melimpah dan mudah didapat yaitu Sargassum cinereum dan limbah baglog Pleurotus ostreotus. Kelemahan ukuran partikel yang kecil adalah sulit dipisahkan dari limbah ketika diaplikasikan, sehingga diperlukan sebuah bentuk atau kemasan biosorben yang memudahkan proses aplikasinya yaitu mengemas dalam kantung teh celup. Tujuan penelitian adalah mendapatkan perbandingan komposisi dan ukuran partikel yang optimum menyerap krom total pada limbah cair batik. Penelitian dilakukan secara eksperimental dengan rancangan petak terpisah. Data yang diperoleh dianalisis menggunakan analisis varian dengan tingkat kesalahan $5 \%$. Hasil penelitian menunjukkan persentase adsorpsi tertinggi terdapat pada perbandingan 3:1 $\mu \mathrm{m}$ sebesar $62.69 \%$. Biosorben yang dikemas dalam kantung teh celup efektif menurunkan krom pada limbah cair batik.
\end{abstract}

Kata kunci : biosorpsi, kantung teh celup, krom, limbah cair batik

\section{Pendahuluan}

Sentra Batik Sokaraja adalah salah satu industri batik rumahan di Kabupaten Banyumas yang berpotensi mencemari lingkungan karena limbahnya dibuang ke Kali Wangan. Limbah cair batik yang dibuang ke Kali Wangan tanpa pengolahan terlebih dahulu dapat mencemari dan mengganggu kehidupan biota air. Kadar TSS, BOD dan COD Kali Wangan sudah melebihi baku mutu lingkungan berturut-turut yaitu $540.13 \mathrm{mg} / \mathrm{L}$; $540.42 \mathrm{mg} / \mathrm{L}$ dan $672.78 \mathrm{mg} / \mathrm{L}$, sedangkan parameter logam berat yang melebihi baku mutu adalah $\mathrm{Cd}$ dan $\mathrm{Cr}$ yaitu $0.018 \mathrm{mg} / \mathrm{L}$ dan 0.231 $\mathrm{mg} / \mathrm{L}$ (Lestari et al., 2015). Krom dalam limbah cair batik dapat menyebabkan menghambat kerja enzim sitokrom monooksigenase. Penghambatan terhadap kerja enzim tersebut dapat menyebabkan kanker pada biota maupun manusia yang terpapar.

Logam berat dalam limbah cair batik dapat dipisahkan secara biologis melalui proses biosorpsi. Proses biosorpsi adalah pengikatan logam melalui adsorpsi dengan menggunakan organisme inaktif atau mati (Okuo et al., 2006). Keunggulan biosorpsi dalam mengadsorpsi logam berat pada limbah adalah prosesnya berlangsung cepat, tingkat penyerapannya tinggi dan selektif (Azmat et al., 2007). Biomassa, waktu kontak, jenis dan luas permukaan biosorben berpengaruh terhadap efektifitas biosorpsi (Alam, 2004). Proses biosorpsi banyak diaplikasikan untuk menurunkan konsentrasi logam pada lingkungan maupun limbah.

Biosorpsi merupakan teknologi alternatif, sehingga biosorben yang digunakan harus murah dan mudah penyediaannya (Sahmoune, et al. 2008). Jenis biosorben yang murah dan keberadaannya melimpah dari spesies alga dan jamur adalah Sargassum cinereum dan Pleurotus ostreatus. S. cinereum mengandung alginat sebagai penukar ion logam berat yang sangat efisien (Rezaee et al., 2006). P. ostreatus adalah jenis fungi pelapuk putih (white rot fungi) yang mempunyai kemampuan menghilangkan bau, mendegradasi pewarna dan menyerap logam berat (Nasreen et al., 2007). P. ostreatus mempunyai nilai ekonomi yang sangat tinggi, sehingga sangat tidak etis jika dimanfaatkan sebagai penyerap logam berat pada limbah. 
Namun $P$. ostreatus dapat diperoleh dari limbah medium tanam jamur (baglog).

Luas permukaan biosorben yang besar dapat meningkatkan jumlah situs aktif yang tersedia untuk pengikatan ion logam berat (Dutta and Basu, 2012). Luas permukaan biosorben ditentukan oleh ukuran partikel. Metode untuk memperluas permukaan dan mudah dipisahkan dari limbah jika diaplikasikan adalah mengemas biosorben dalam kantung teh celup. Keunggulan biosorben tersebut adalah tidak menimbulkan dampak lanjutan berupa TSS dan sedimentasi.

Tujuan penelitian adalah mendapatkan perbandingan komposisi dan ukuran biosorben yang dikemas dalam kantung teh celup yang optimum dalam mengadsorpsi krom total pada limbah cair batik.

\section{Metode}

Penelitian dilakukan di Laboratorium Lingkungan Fakultas Biologi Universitas Jenderal Soedirman pada bulan Mei - September 2015. Penelitian dilakukan secara eksperimental. Rancangan yang digunakan adalah Rancangan Petak Terpisah (Spilt Plot Design). Perlakuan yang dicobakan yaitu komposisi campuran $S$. cinereum dan limbah baglog $P$. ostreatus sebagai main plot dan ukuran partikel biosorben sebagai sub plot. Campuran $S$. cinereum dan limbah baglog $(\mathrm{M})$ terdiri dari 5 taraf dengan perbanding yaitu :

$\mathrm{M} 1=S$. cinereum $:$ limbah baglog $=1: 0$

$\mathrm{M} 2=S$. cinereum $:$ limbah baglog $=3: 1$

$\mathrm{M} 3=S$. cinereum $:$ limbah baglog $=1: 1$

M4 $=S$. cinereum $:$ limbah baglog $=1: 3$

M5 $=S$. cinereum : limbah baglog $=0: 1$

sedangkan ukuran partikel biosorben(U) terdiri dari 3 taraf yaitu :

$$
\begin{aligned}
& \text { U1 }=425-675 \mu \mathrm{m} \\
& \text { U2 }=250-425 \mu \mathrm{m} \\
& \text { U3 }=150-250 \mu \mathrm{m}
\end{aligned}
$$

Semua perlakuan dikombinasikan dan diulang 3 kali sehingga diperoleh 45 unit perlakuan.

\section{Persiapan Biosorben}

Biosorben terdiri dari campuran S. cinereum dan limbah baglog $P$. ostreatus. S. cinereum diambil dari pantai Rancababakan Cilacap Indonesia. Limbah media tanam jamu (baglog) diperoleh dari tempat budidaya jamur $P$. ostreatus Pabuaran, Purwokerto, Indonesia. Limbah baglog yang digunakan adalah baglog yang sudah habis masa panennya. S. cinereum dan limbah baglog dicuci dengan air deionisasi yang mengalir (Sahmoune, Louhab and Boukhiar, 2008). Biosorben dikeringkan di bawah sinar matahari selama 24 jam, dan dikeringkan dalam oven pada suhu $70^{\circ} \mathrm{C}$ hingga berat konstan. Biosorben kemudian diblender dan diayak. Ukuran partikel
452-672 $\mu \mathrm{m}$ adalah biosoben yang lolos pada sieve 20 dan tertahan pada sieve 40 . Ukuran partikel 250-425 $\mu \mathrm{m}$ adalah biosoben yang lolos pada sieve 40 dan tertahan di sieve 60, sedangkan ukuran partikel 150-250 $\mu \mathrm{m}$ adalah biosorben yang lolos pada sieve 60 dan tertahan pada sieve nomor 100 . Biosorben diaktivasi pada larutan $0,1 \mathrm{M} / \mathrm{L} \mathrm{HCl}$ selama 30 menit (setiap $50 \mathrm{~g}$ biosorben dalam $1 \mathrm{~L}$ larutan) (Khorramabadi and Soltani, 2008). Biosorben kemudian dikeringkan dalam oven pada suhu $70^{\circ} \mathrm{C}$ selama 24 jam.

\section{Pembuatan Biosorben dalam kantung teh celup}

Biosorben ditimbang sebanyak $500 \mathrm{mg}$ dengan komposisi sesuai perlakuan. Biosorben dibungkus kertas teh celup ukuran $4 \times 6 \mathrm{~cm}$. Biosorben yang dikemas dalam kantung teh celup siap digunakan.

\section{Persiapan limbah cair batik}

Limbah cair batik diambil dari Sentra Batik Sokaraja di Dusun Kauman, Desa Sokaraja Kulon Kecamatan Sokaraja, Kabupaten Banyumas, Jawa Tengah. Limbah cair yang digunakan adalah sisa pewarnaan dan pencelupan. Limbah diambil dari 4 industri rumahan yang berbeda dengan pertimbangan adanya perbedaan jenis pewarna yang digunakan. Keempat jenis limbah kemudian dicampur dan $\mathrm{pH}$ awal limbah diatur menjadi 8.

\section{Percobaan biosorpsi skala laboratorium}

Erlenmeyer volume $250 \mathrm{~mL}$ disediakan sebanyak 45 buah, masing-masing diisi dengan $100 \mathrm{~mL}$ limbah cair batik. Setiap erlenmeyer ditambahkan 1 buah biosorben yang dikemas dalam kantung teh celup dengan komposisi dan ukuran partikel sesuai perlakuan. Erlenmeyer ditutup dengan paraffin dan dihomogenkan dalam shaker inkubator dengan kecepatan $175 \mathrm{rpm}$ pada suhu $25^{\circ} \mathrm{C}$ selama 1 jam.

\section{Ekstraksi Limbah Cair Batik}

Limbah cair batik dipisahkan dari biosorben, kemudian diambil $50 \mathrm{ml}$ dan ditambahkan $5 \mathrm{~mL}$ $\mathrm{HNO}_{3}$ pekat dan $2 \mathrm{~mL} \mathrm{HCl} \mathrm{20 \%}$. Larutan dipanaskan dengan hot plate pada suhu $180^{\circ} \mathrm{C}$ hingga tersisa $10-20 \mathrm{~mL}$. Larutan disaring dengan kertas Whatman No. 42, kemudian filtrat diencerkan dengan aquades hingga $50 \mathrm{~mL}$. Filtrat diukur absorbansi $\mathrm{Cr}$ dengan alat AAS dengan panjang gelombang $357 \mathrm{~nm}$ (Herlich, 1991).

\section{Metode Analisis}

Data yang diperoleh berupa persentase adsorpsi $\mathrm{Cr}$ total dianalisis dengan menggunakan uji $\mathrm{F}$ dengan tingkat kepercayaan $95 \%$ untuk mengetahui adanya pengaruh antar perlakuan kemudian dilanjutkan dengan Uji Beda Nyata Terkecil (BNT) untuk mengetahui campuran $S$. cinerium dan limbah baglog dan ukuran partikel 
yang paling optimum dalam mengadsorpsi $\mathrm{Cr}$ total.

\section{Hasil dan Pembahasan}

Berdasarkan hasil penelitian yang telah dilakukan, pada kondisi optimum adsorpsi yaitu $\mathrm{pH}$ awal limbah cair batik 8 dan waktu kontak 1 jam, absorbansi AAS memperlihatkan adanya perbedaan jumlah konsentrasi krom pada limbah cair batik sebelum dengan sesudah perlakuan. Besarnya krom yang teradsorpsi pada perlakuan biosorben yang dikemas dalam kantung teh celup berbeda-beda, tergantung pada perbandingan dan ukuran partikel. Konsentrasi krom total limbah cair batik sebelum biosorpsi di Sentra Batik Sokaraja berkisar 0,1407 - 0,3485 mg/L dengan rata-rata $0,1893 \mathrm{mg} / \mathrm{L}$. Gambar 1. menunjukkan bahwa persentase adsorpsi krom total tertinggi sebesar $62,69 \%$ dari konsentrasi awal 0,744 mg/L menjadi $0,156 \mathrm{mg} / \mathrm{L}$ terdapat pada perbandingan biosorben 3:1 dengan ukuran partikel 150-250 $\mu \mathrm{m}$ dan persentase terrendah sebesar $47,36 \%$ dari konsentrasi awal 0,165 mg/L menjadi 0,075 mg/L terdapat pada perbandingan biosorben 1:0 dengan ukuran partikel 425-675 $\mu \mathrm{m}$.

Berdasarkan hasil analisis varian, persentase adsorpsi krom total dengan perlakuan perbandingan biosorben dan interaksi antara perbandingan dan ukuran partikel biosorben menunjukkan hasil tidak berbeda nyata, sedangkan perlakuan ukuran partikel menunjukkan berbeda nyata (Tabel 1.) sedangkan rerata persentase adsorpsi krom total pada berbagai ukuran partikel menunjukkan tidak berbeda nyata (Tabel 2.).

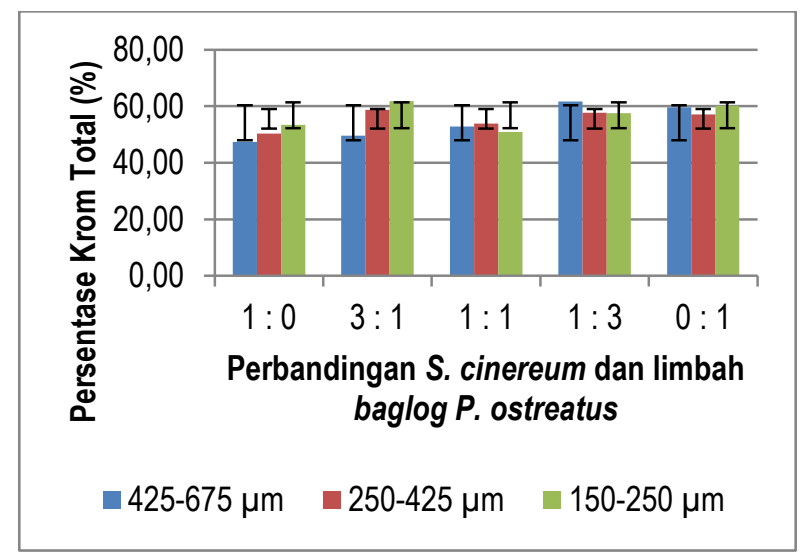

Gambar 1. Persentase adsorpsi Krom total pada limbah cair batik dengan biosorben yang dikemas dalam kantung teh celup pada perbandingan dan ukuran partikel berbeda
Tabel 1. Analisis varian adsorpsi $\mathrm{Cr}$ Total pada limbah cair batik dengan biosorben yang dikemas dalam kantung teh celup pada perbandingan dan ukuran partikel berbeda

\begin{tabular}{lcrrrrr}
\hline $\begin{array}{l}\text { Sumber } \\
\text { Ragam }\end{array}$ & $\begin{array}{c}\text { Derajat } \\
\text { Bebas }\end{array}$ & $\begin{array}{c}\text { Jumlah } \\
\text { Kuadrat }\end{array}$ & $\begin{array}{r}\text { Kuadrat } \\
\text { Tengah }\end{array}$ & $\begin{array}{c}F \\
\text { hitung }\end{array}$ & \multicolumn{2}{c}{ Ftabel } \\
\cline { 6 - 8 } & 14 & $1.135,604$ & 81,115 & $1,165^{\mathrm{ns}}$ & 3,23 & 0.01 \\
\hline Perlakuan & 14 & 9,943 & 4,972 & $0,071^{\mathrm{ns}}$ & 4,46 & 8,65 \\
Kelompok & 2 & & 9,943 & & \\
Komposisi & 4 & 568,588 & 142,147 & $2,041^{\mathrm{ns}}$ & 3,64 & 7,01 \\
Galat a & 8 & 557,073 & 69,634 & & & \\
Ukuran & & & & & & \\
Partikel & 2 & 41,870 & 20,935 & $3,813^{*}$ & 3,49 & 5,85 \\
Interaksi & 8 & 332,263 & 41,533 & $1,108^{\mathrm{ns}}$ & 2,45 & 3,56 \\
Galat b & 20 & 109,818 & 5,491 & & & \\
Total & 44 & $3.395,159$ & & & & \\
\hline
\end{tabular}

Keterangan : ns $=$ non signifikan; ${ }^{*}=$ berbeda nyata

Tabel 2. Rerata uji BNT ukuran partikel yang mengadsorpsi $\mathrm{Cr}$ total

\begin{tabular}{cc}
\hline Ukuran Partikel $(\mu \mathrm{m})$ & Adsorpsi Krom Total $(\%)$ \\
\hline $150-250$ & $54,395 \mathrm{a}$ \\
$250-425$ & $55,512 \mathrm{a}$ \\
$425-625$ & $56,756 \mathrm{a}$ \\
\hline Keterangan: angka yang diikuti huruf yang sama tidak berbeda
\end{tabular}

Keterangan: angka yang diikuti huruf yang sama tidak berbeda berdasarkan BNT pada tingkat kepercayaan $95 \%$

Pada Gambar 1 menunjukkan bahwa persentase adsorpsi pada perbandingan biosorben 1:0 dan 3:1 terus meningkat mulai dari ukuran partikel 425-675 $\mu \mathrm{m}$ hingga 150-250 $\mu \mathrm{m}$. Hal tersebut menunjukkan bahwa semakin besar permukaan biosorben semakin besar kapasistas adsorpsi. Persentase adsorpsi pada perbandingan biosorben 1:1 meningkat hingga ukuran partikel 250-425 $\mu \mathrm{m}$ kemudian menurun pada ukuran partikel 150-250 $\mu \mathrm{m}$. Penurunan tersebut disebabkan ukuran partikel 150-250 $\mu \mathrm{m}$ lebih kecil dibandingkan pori-pori kantung teh celup sehingga, banyakn biosorben yang lolos dari kantung teh celup. Hal tersebut menyebabkan gugus aktif yang tersedia untuk mengikat krom berkurang. Demikian juga halnya pada perbandingan biosorben 1:3 yang persentase adsorpsinya terus menurun dari ukuran partikel 425-675 $\mu \mathrm{m}$ hingga 150-250 $\mu \mathrm{m}$. Persentase adsorpsi pada perbandingan biosorben 0:1 menurun pada ukuran partikel 250$425 \mu \mathrm{m}$. Persentase adsorpsi krom menggunakan biosorben $300 \mathrm{mg} S$. cinereum yang dipotong ukuran $1 \mathrm{~cm}$ sebesar 17,22\% (Lestari et al., 2008). Ukuran partikel 425-675 $\mu \mathrm{m}$ memiliki persentase adsorpsi lebih tinggi dibanding ukuran partikel 1 $\mathrm{cm}$. Adsorpsi $\mathrm{Zn}$ pada limbah cair batik menggunakan limbah baglog $P$. ostreatus pada bobot $25 \mathrm{~g}$ sebesar $62,40 \%$ (Kartikasari et al., 2012). Biomassa yang digunakan dalam penelitian adalah $500 \mathrm{mg}$ dengan ukuran partikel 425-675 $\mu \mathrm{m}$ memiliki persentase adsorpsi hampir sama dengan berat biomassa $25 \mathrm{~g}$ utuh. Hal tersebut menunjukkan bahwa ukuran partikel kecil dapat meningkatkan kapasistas adsorpsi. 
Penurunan kemampuan adsorpsi $\mathrm{Cr}$ total pada ukuran partikel 150-250 $\mu \mathrm{m}$ disebabkan oleh situs aktif telah jenuh dengan ion krom sehingga penambahan luas permukaan biosorben tidak meningkatkan adsorpsi krom total karena proses desorpsi. Desorpsi terjadi diakibatkan oleh sisi aktif atau rongga-rongga kosong telah terisi seluruhnya atau telah jenuh sehingga tidak mampu lagi melakukan adsorpsi (Bina et al., 2006; Hammaini et al., 2007). Satu situs aktif yang terdapat pada permukaan biosorben hanya dapat mengikat satu ion krom pada limbah cair batik. Sheng et al., (2004); Chen et al., (2005) menyatakan bahwa adsorpsi pada lapisan tunggal hanya akan menyediakan satu situs aktif untuk satu molekul. Proses adsorpsi logam berat oleh $S$. cinereum dan limbah baglog terjadi karena adanya interaksi antara situs yang bermuatan negatif yang terdapat pada dinding sel berupa fosfodiester, karboksilat, fosfat, thiolat dan gugus amida dengan ion krom pada limbah cair batik yang bermuatan positif.

Penurunan adsorpsi krom totaldiduga juga disebabkan berkurangnya biomassa yang tersedia karena sebagian besar perlakuan pada ukuran partikel 150-250 $\mu \mathrm{m}$ lolos dari kantung teh celup. Hal tersebut sesuai dengan berkurangnya biomassa akhir pada ukuran partikel 150-250 $\mu \mathrm{m}$ yaitu $438.33 \mathrm{mg}$. Volesky and Holan, (1995) mengemukakan bahwa biomassa berpengaruh terhadap kapasitas adsorpsi. Kapasitas adsorpsi akan terus meningkat dengan bertambahnya biomassa hingga titik jenuh.

Tabel 1. menunjukkan bahwa perbandingan biosorben dan interaksi tidak berpengaruh terhadap adsorpsi krom total sedangkan ukuran partikel berpengaruh terhadap adsorpsi krom total. Proses adsorpsi adalah proses pengikatan logam pada dinding atau permukaan biosorben. Situs aktif biosorben bertanggung jawab terhadap besarnya kapasitas adsorpsi. Situs aktif biosorben dapat diperbanyak dengan memperbesar luas permukaan. Permukaan biosorben semakin luas dengan ukuran partikel yang kecil. Hal tersebut menunjukkan bahwa besarnya adsorpsi krom total pada limbah cair batik sangat dipengaruhi oleh ukuran partikel.

Rerata persentase adsorpsi krom total pada berbagai ukuran partikel menunjukkan bahwa ukuran partikel 425-625 $\mu \mathrm{m}$ mengadsorpsi krom total terbaik yaitu sebesar $56,756 \%$ (Tabel 2). Ukuran partikel berpengaruh terhadap jumlah situs aktif yang mengikat logam, semakin banyak situs aktif maka akan semakin banyak ion logam berat yang teradsorpsi sampai pada suatu titik jenuh tertentu (Al-Qodah, 2006; Montazer-rahmati et al., 2011) Ukuran partikel 150-250 $\mu \mathrm{m}$ merupakan ukuran partikel terkecil yang dicobakan, namun hasil penelitian tidak menunjukkan adsorpsi yang tinggi karena biosorben dalam kantung teh celup lolos atau keluar melewati pori kantung teh celup sehingga mengurangi jumlah situs aktif yang tersedia. Selain itu, kemasan teh celup membuat biosorben menggumpal ketika dikontakkan dengan limbah cair, sehingga ada kemungkinan situs aktif bagian dalam tidak dapat berikatan dengan ion krom dalam limbah cair batik. Situs aktif yang berikatan dengan logam hanya bagian permukaan saja. Adsorpsi logam berat menggunakan rumput laut (seaweed) sangat dipengaruhi oleh jumlah biomassa biosorbennya (Rezaee et al., 2006).

\section{Simpulan}

Perbandingan biosorben yang optimum dalam mengadsorpsi krom total pada limbah cair batik adalah 3:1 dengan ukuran partikel 425-675 $\mu \mathrm{m}$. Biosorben yang dikemas dalam kantung teh celup efektif meskipun terjadi penggumpalan pada saat kontak dengan limbah cair batik. Penelitian lebih lanjut perlu dilakukan untuk mengkaji biomassa optimal agar tidak menggumpal dalam kantung teh celup.

\section{Daftar Referensi}

Al-Qodah, Z. (2006) 'Biosorption of heavy metal ions from aqueous solutions by activated sludge', Desalination, 196, pp. 164-176.

Alam, Z. (2004) 'Biosorption of Basic Dye Using Sewage Treatment Plant Biosolid', Biotechnology, 3(2), pp. 200-2004.

Azmat, R., Uzma and Uddin, F. (2007) 'Biosorption of Toxic Metals from Solid Sewage Sludge by Marine Green Algae', Asian Journal of Plant Sciences, 6(1), pp. 42-45.

Bina, B. et al. (2006) 'Biosorption and Recovery of Copper and Zinc from Aqueous Solutions by Nonliving Biomass of Marine Brown Algae of Sargassum Sp.', Pakistan Journal of Biological Science, 9(8), pp. 1525-1530.

Chen, X. C. et al. (2005) 'Biosorption of copper ( II ) and zinc ( II ) from aqueous solution by Pseudomonas putida CZ1', Colloids and Surface, 46, pp. 101-107. doi: 10.1016/j.colsurfb. 2005.10.003.

Dutta, Monal and Basu, J. K. (2012) 'Statistical Optimization for the Adsorption of Acid Fuchsin onto the Surface of Carbon Alumina Composite Pellet: an Application of Response Surface Methodology', Journal of Environmental Science and Technology, 5(1), pp. 42-53.

Hammaini, A. et al. (2007) 'Biosorption of Heavy Metals by Activatied Sludhe and Their 
Desorption Characteristics', Journal of Environment Management, 84, pp. 419-426. doi: 10.1016/j.jenvman.2006.06.015.

Herlich, K. (1991) Official Methods of Analisis. Virginia USA: AOAC.

Kartikasari, T. H., Lestari, S. and Dewi (2012) 'Adsorpsi Zn dan dekolorisasi limbah batik menggunakan limbah baglog Pleurotus ostreatus dengan sistem inkubasi dan volume limbah batik berbeda', Biosfera, 29(3), pp. 167-173.

Khorramabadi, G. S. and Soltani, R. D. C. (2008) 'Evaluation of the Marine Algae Gracilaria salicornia and Sargassum sp. for the Biosorption of $\mathrm{Cr}(\mathrm{VI})$ from Aqueous Solutions', Journal of Applied Sciences, 8(11), pp. 21632167.

Lestari, S. et al. (2015) 'Kajian Kualitas Air Kali Wangan yang Tercemar Limbah Cair Batik', in Pengelolaan Sumber Daya Alam dan Lingkungan. Semarang, pp. 553-556.

Lestari, S., Hernayanti and Insan, A. I. (2008) 'Biosorpsi Krom Hexavalen (CrVI) menggunakan rumput laut Sargassum sp. dalam skala laboratorium', Biosfera, 25(3), pp. 129-134.

Montazer-rahmati, M. M. et al. (2011) 'Kinetics and equilibrium studies on biosorption of cadmium, lead, and nickel ions from aqueous solutions by intact and chemically modified brown algae', Journal of Hazardous Materials.
Elsevier B.V., 185(1), pp. 401-407. doi: 10.1016/j.jhazmat. 2010.09.047.

Nasreen, Z., Rukhsana, B. and Tasnim, K. (2007) 'Decolorization of Textile Dyes and Their Effluents Using White Rot Fungi', Mycopath, 5(1), pp. 49-52.

Okuo, J. M., Sanni, S. B. and Aigbedio, S. . (2006) 'Selective Biosoption of Heavy Metal lons from Aqueous Solutions by Pre-Treated Negerian Fresh Water Algae', Trends in Applied Sciences Research, 1(1), pp. 83-90.

Rezaee, A. et al. (2006) 'Biosorption of Mercury by Biomass of Filamentous Algae Spirogyra Spesies', Journal of Biological Sciences, 6(4), pp. 695-700.

Sahmoune, M. N., Louhab, K. and Boukhiar, A. (2008) 'The Adsorption of Chromium from Aqueous Solution Using Dead Biomass', Environment Research Journal, 2(5), pp. 254260.

Sheng, P. X. et al. (2004) 'Sorption of lead, copper, cadmium, zinc, and nickel by marine algal biomass: characterization of biosorptive capacity and investigation of mechanisms', Journal of Colloid and Interface Science, 275, pp. 131-141. doi: 10.1016/j.jcis.2004.01.036.

Volesky, B. and Holan, Z. R. (1995) 'Biosorption of heavy metals.', Biotechnology progress, 11(3), pp. 235-250. doi: 10.1021/bp00033a001. 